\title{
The distribution of stanniocalcin 1 protein in fetal mouse tissues suggests a role in bone and muscle development
}

\author{
W-Q Jiang ${ }^{1}$, A C-M Chang ${ }^{1}$, M Satoh $^{3}$, Y Furuichi ${ }^{3}$, P P L Tam ${ }^{2}$ \\ and R R Reddel ${ }^{\mathbf{1}}$ \\ ${ }^{1}$ Cancer Research Unit, Children's Medical Research Institute, 214 Hawkesbury Road, Westmead, NSW 2145, Australia \\ ${ }^{2}$ Embryology Unit, Children's Medical Research Institute, 214 Hawkesbury Road, Westmead, NSW 2145, Australia \\ ${ }^{3}$ AGENE Research Institute, 200 Kajiwara, Kamakura, Kanagawa 247, Japan \\ (Requests for offprints should be addressed to R R Reddel, Children's Medical Research Institute, Locked Bag 23, Wentworthville, NSW 2145, Australia; \\ Email: rreddel@.cmri.usyd.edu.au)
}

\begin{abstract}
We previously isolated a mammalian gene STC1 that encodes a glycoprotein related to stanniocalcin (STC), a fish hormone that plays a major role in calcium homeostasis. However, the mammalian STC1 gene is expressed in a variety of adult tissues in contrast to fish where STC is expressed only in one unique gland, the corpuscles of Stannius. This suggested that STC1 may have wider autocrine/paracrine functions in mammals. In the present study, using immunocytochemistry, we showed that STC1 protein is localized in the developing bone and muscle of the mouse fetus. During endochondral bone
\end{abstract}

formation, STC1 is found principally in prechondrocytes and prehypertrophic chondrocytes. During intramembranous bone formation STC1 is present in the mesenchyme that is about to undergo ossification. STC1 is also found in the myocardiocytes of the developing heart and at all stages of differentiation from myoblasts to myotube formation in developing skeletal muscle. The specific localization of STC1 to chondrocytes and muscle cells suggests a role for this protein in chondrogenic and myogenic differentiation. Journal of Endocrinology (2000) 165, 457-466

\section{Introduction}

The recently discovered mammalian stanniocalcin (STC) gene family currently has two known members, STC1/ Stc1 (Chang et al. 1995, 1996, Olsen et al. 1996) and STC2/Stc2 (Chang \& Reddel 1998, DiMattia et al. 1998, Ishibashi et al. 1998), that have about 40\% homology at the N-termini of their encoded proteins. The functions of STC1 and STC2 are unknown, but STC1 mRNA has recently been shown to be induced in serum-stimulated fibroblasts (Iyer et al. 1999) and both are homologous to a fish glycoprotein hormone, STC, that has an important role in calcium and phosphate homeostasis. Fish STC is secreted by the corpuscles of Stannius, endocrine glands associated with the kidney (Stannius 1839, Wagner et al. 1986, 1992, Butkus et al. 1987, 1989). Surgical removal of the corpuscles of Stannius results in marked hypercalcemia, from which it has been concluded that the normal action of STC in fish is to decrease the level of circulating calcium (Fontaine 1964, So \& Fenwick 1979, Lafeber \& Perry 1988). In support of this conclusion it has been found that experimentally increased plasma calcium results in elevated STC secretion (Lafeber \& Perry 1988, Wagner et al. 1989, 1991). A related action of fish STC is stimulation of phosphate reabsorption by renal proximal tubule cells ( $\mathrm{Lu}$ et al. 1994), which may be expected to result in decreased plasma calcium through increased deposition of calcium phosphate in bones.

Human and mouse STC1 proteins are closely related to each other (98\% amino acid similarity) and share about $80 \%$ amino acid sequence similarity with fish STC, indicating that this protein is highly conserved during evolution; STC2 is much less closely related. Like fish STC, recombinant human STC1 (rhSTC1) is able to inhibit uptake of calcium through the gills when injected into goldfish (Olsen et al. 1996). rhSTC1 can also inhibit renal phosphate excretion when injected into rats (Wagner et al. 1997), consistent with the action of fish STC in stimulating phosphate reabsorption by kidney cells (Lu et al. 1994). It is tempting to conclude, therefore, that the mammalian STCs may also have a role in calcium and phosphate homeostasis. The relevance of these observations to mammalian physiology is still unknown, however, because in contrast to fish STC, which is expressed only in an endocrine gland, viz. the corpuscle of Stannius (Sterba et al. 1993), mammalian STC1 and 2 are expressed in a variety of tissue types (Chang et al. 1995, 1996, Chang \& Reddel 1998, Ishibashi et al. 1998). 
As a step towards determining the functions of mammalian STCs, we have examined by immunocytochemistry the distribution of STC1 in mouse fetuses. Previous studies have focused mainly on postnatal kidney (De Niu et al. 1998, Wong et al. 1998) and, to a lesser extent, brain (Zhang et al. 1998) and ovary (Varghese et al. 1998). Here we show for the first time that during mouse development STC1 is predominantly localized in bones and muscles. These findings suggest a role for STC1 in skeleton and muscle development.

\section{Materials and Methods}

\section{Generation of recombinant protein and antibody}

rhSTC1 proteins were expressed in E. coli. The DNA sequence encoding human STC1 protein was amplified using PCR primers corresponding to the start and the end of the coding region (GenBank accession no. U25997). The $5^{\prime}$ primer has the sequence $5^{\prime}$-ATTGGATCCAGT GCTTCTGCAACCCATGA and contains a BamHI restriction enzyme site (underlined) followed by codons for amino acid residues 14-20. The $3^{\prime}$ primer has the sequence 5'-TTAAGCTTATATGCACTCTCATGG GATGT and contains a HindIII site (underlined) plus a sequence encoding the last seven codons of STC1. The PCR-amplified product, after digestion with enzymes BamHI and HindIII, was subcloned into the BamHIHindIII site of expression vector PMD1 (Qiagen, Clifton Hill, Victoria, Australia) and transformed into E. coli strain M15[pREP4] (Qiagen). The vector PMD1 contains the peptide MRGS followed by a 6-His epitope tag to facilitate purification of recombinant proteins by metalaffinity chromatography. The resultant recombinant STC1 protein has the sequence $\mathrm{MRGSH}_{6}$ at its $\mathrm{N}$-terminus followed by the STC1 sequence from residue 14 onwards. E. coli containing the recombinant plasmid was grown to an $\mathrm{OD}_{600}$ (optical density measured at wavelength $600 \mathrm{~nm}$ ) between 0.4 and 0.6 before induction with isopropylthio- $\beta$-D-galactoside to a final concentration of $1 \mathrm{mM}$. The culture was grown for a further 3-4 h before harvesting by centrifugation. The cell pellet was solubilized in $6 \mathrm{M}$ guanidinium hydrochloride and the recombinant protein purified using a nickel-nitrilotriacetic acid (Ni-NTA) column according to the manufacturer's instructions (Novagen, Milwaukee, WI, USA).

Polyclonal antibody against the expressed STC1 protein was generated using two New Zealand white rabbits. The rabbits were injected i.d. at multiple sites with $0.2 \mathrm{mg}$ protein as an emulsion in Freund's complete adjuvant. Booster injections were done with the same immunogen emulsified in Freund's incomplete adjuvant four times at intervals of 2 weeks. Seven days after each injection, the rabbits were bled from ear veins for testing of the antibody titers. Testing was performed by enzyme-linked immunosorbent assay (ELISA) utilizing microtiter plates coated with the antigen and detected with alkaline phosphataselabeled goat anti-rabbit IgG antibody (Zymed, South San Francisco, CA, USA). The antiserum was harvested from the rabbit showing the highest titer after five immunizations, and was subsequently affinity purified using $3.6 \mathrm{mg}$ immunizing antigen immobilized on a HiTrap N-hydroxy-succinimide NHS-activated column (Pharmacia, North Ryde, NSW, Australia). Specificity of the antibody was demonstrated as follows. Staining of tissue sections was abolished by preabsorption of the STC1 antibodies with baculoviral rhSTC1 (D Jellinek, unpublished data) (see Fig. 5A). Furthermore, the antibody detected a protein of the predicted size on immunoprecipitation from lysates of insect cells infected with a recombinant baculovirus expressing STC1. In addition, immunocytochemistry with this antibody was positive for STC1 in the STC1-baculoviral infected insect cells but not in non-infected cells. Finally, the antibody also immunoprecipitated STC1 from medium conditioned by human cell lines that secrete STC1 but not from control medium (D Jellinek, A Chang \& R Reddel, unpublished data).

\section{Mice}

Mice were maintained and handled in accordance with the Australian Code of Practice for the Care and Use of Animals for Scientific Purposes. Embryos at 7.5-15.5 days post coitum ( $=\mathrm{E} 7 \cdot 5$ to $\mathrm{E} 15.5$; plug day $=0.5$ days) were collected from pregnant $(\mathrm{C} 57 \mathrm{BL} / 6 \times \mathrm{DBA} / 2) \mathrm{F} 1$ mice. Embryos were removed from the uteri, fixed in $4 \%$ buffered formaldehyde and embedded in paraffin wax.

\section{Immunocytochemistry}

Ten-micron sagittal and transverse sections were cut with a Jung Ultra Microtome (Leica, Wetzlar, Germany) and were mounted on superfrost slides (Menzel, Braunschweig, Germany). Sections were dewaxed and rehydrated. To block non-specific staining, the sections were first incubated with 5\% normal goat serum at room temperature (RT) for $30 \mathrm{~min}$. They were then incubated with the rabbit anti-STC1 antibody $(1: 200)$ at $4{ }^{\circ} \mathrm{C}$ overnight, followed by incubation with Texas Redconjugated goat anti-rabbit IgG (1:60; Vector, Burlingame, CA, USA) and 4',6-diamidino-2phenylindole (DAPI; 20 ng/ml; Sigma-Aldrich Pty Ltd, Castle Hill, NSW, Australia) at RT for $30 \mathrm{~min}$. Each incubation step was followed by three washes with PBS. Finally, the preparations were mounted in 90\% glycerol/ $10 \%$ PBS. Negative controls were performed using normal rabbit serum instead of the anti-STC1 antibodies.

For the staining of collagen X, sections were first treated with a mixture of $0 \cdot 2 \%$ trypsin (Sigma type II-S) and $0 \cdot 1 \%$ testicular hyaluronidase (Sigma type IV-S) at RT for $20 \mathrm{~min}$, and then incubated with rabbit polyclonal 
antibody against mouse collagen X (Kwan et al. 1997). The remainder of the procedure was the same as for STC1 staining.

The preparations were examined under a fluorescence microscope (Leica). The image was captured by an intensified video camera (Panasonic, Osaka, Japan) or a Spot cooled CCD camera (Diagnostic Instruments, Sterling Heights, MI, USA).

\section{Results}

STC1 is associated with endochondral and membranous bone formation

STC1 staining first appeared in the cranial mesenchyme of E9. 5 embryos and continued to be found in E10.5 cranial mesenchyme (Fig. 1A and B), which later forms parts of the chondrocranium (Fig. 1C). In contrast, STC1 was not found initially in the sclerotome (Fig. 1D) and only appeared as the sclerotome condensed into the prevertebrae (Fig. 1E and F). Subsequently in the vertebral column (Fig. 1 G), STC1 was found in the chondrocytes of the developing vertebral body. Strong STC1 staining was seen in the intervertebral disk, which is derived from the notochord. STC1 staining was more intense in the cranial region of the notochord (Fig. 1B) while it was weak in the trunk region (Fig. 1D and F).

The distribution of STC1 in the paraxial mesoderm along the rostro-caudal body axis was examined to explore the dynamics of STC1 distribution during the differentiation and maturation of chondrocytes in the developing vertebral column. In a single section at E14 5 , cells can be seen in various stages of maturation, being least advanced in the caudal region. STC1 was observed in prechondrocytes of the condensing sclerotome (Fig. 2A), but not in the cells that had become young chondrocytes (Fig. 2B). Immunostaining was seen again in chondrocytes at the prehypertrophic phase (Fig. 2C). In the rostral part of the vertebral column, STC1 staining in the central core of the vertebral body decreased as the chondrocytes in this region underwent hypertrophic differentiation (Fig. 2D), and diminished 1 day later upon ossification (Fig. 2E). In the ossifying vertebral body, STC1-immunoreactive cells envelop the STC1-negative core of hypertrophic chondrocytes (Fig. 3A). The STC1-positive cells correspond to the cells of the transitional zone between the proliferative and hypertrophic chondrocytes, the latter being readily identified by staining of collagen $\mathrm{X}$ (Fig. 3A).

The STC1 distribution pattern was also analyzed in long bones. Immunostaining of STC1 in the ulna of an E15.5 forelimb showed that STC1-positive chondrocytes were localized almost exclusively to the transitional layer between the proliferating and hypertrophic zones, while STC1 was not detected in either the proliferating or hypertrophic zones, or in the zone of ossification (Fig. 3B).
This is consistent with the distribution pattern of STC1 in the ossifying vertebral body.

In contrast to the vertebrae and long bones, chondrocytes in the otic capsule at E15.5 are more uniform in their stage of differentiation, and at that stage STC1 staining was found in most cells of the cartilaginous capsule (Fig. 3C). STC1 staining was also uniform in the cartilaginous nasal septum (Fig. 3D). Moreover, STC1 staining was evident in the Meckel's cartilage derived from neural crest (Fig. $3 \mathrm{E}$ ), and the mesenchymal condensation of membranous mandible (Fig. 3E) and maxilla (not shown).

Taken together, these data indicate that STC1 may be involved in chondrocytic differentiation and maturation during endochondral bone formation, and may also have a role in membranous bone formation.

\section{STC1 is found in myogenic cells}

Other STC1-immunoreactive tissues include skeletal and cardiac muscles. Skeletal muscles are mainly derived from the myotome of the somite. Muscle differentiation commences with the aggregation of myoblasts, followed by the alignment and fusion of cells, and finally the formation of multi-nucleated myotubes (DAPI staining, Fig. 4A-C). STC1 staining appeared in the myoblasts during myotomal condensation (Fig. 4A), and increased in intensity as the myoblasts aligned to start fusion (Fig. 4B). The myotubes exhibited patchy STC1 staining along their length (Fig. 4C). Moreover, STC1 was present in the skeletal muscles from the back, abdominal wall and limb (Fig. 4D-F), and no apparent difference in STC1 staining was detected among these muscle groups.

In the heart, STC1 first appeared at E8.5 (Fig. 5A). STC1 staining was prominent in the myocardium of the atrium and the ventricle at E11.5, but was absent from the endocardial cushion (Fig. 5B). At E13.5, there was less STC1 staining in the muscular trabeculae of the ventricles (Fig. 5C), and by E15.5, staining was nearly absent from the heart (data not shown).

No STC1 staining was found in the smooth muscles of the esophagus and intestine (Fig. 5D and E). In these sections, STC1 was found in the basal layer of the stratified mucous epithelium of the esophagus (Fig. 5D), while it was absent from the mucous epithelium of the intestine (Fig. 5E). STC1 staining was also evident in the oral epithelium (Fig. 3E).

\section{Discussion}

The data presented in this study strongly suggest a role for STC1 in endochondral and membranous bone formation. This notion is indirectly supported by a recent report which showed that STC1 mRNA is expressed in endochondral and membranous bones of 20- or 30-day-old mice, implicating the involvement of STC1 in bone 

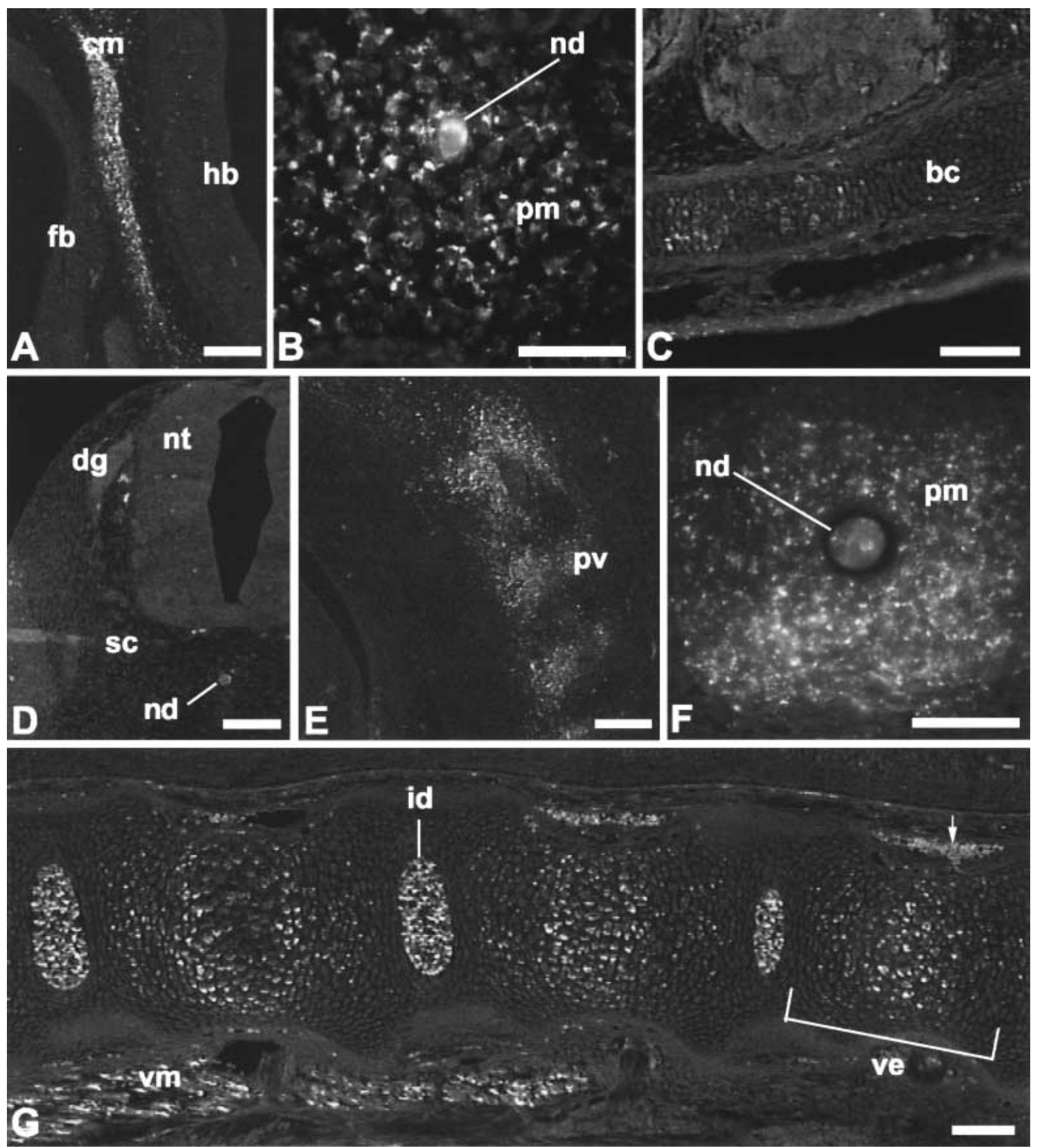

Figure 1 Distribution of STC1 in chondrogenic tissues. (A) At E10.5, STC1 is present in the cranial mesenchyme (cm). (B) At E10.5, it is also present in the peri-notochordal mesenchyme $(\mathrm{pm})$ in the head that later forms parts of the chondrocranium including $(\mathrm{C})$ the basisphenoid cartilage (bc) shown at E14.5. (D) STC1 is not found in the sclerotome (sc) at E10.5, but as shown in (E) and (F) it is seen at E12.5 as the sclerotome condenses to form the pre-vertebra (pv). (G) In the vertebral column at E15.5, STC1 staining is found in the developing vertebral bodies (the bracket indicates the domain of a vertebra (ve)), as well as in the intervertebral disk (id). The arrow in (G) indicates false signals due to autofluorescence of blood cells. Other abbreviations: $d g$, dorsal root ganglion; fb, forebrain; $\mathrm{hb}$, hindbrain; nd, notochord; nt, neural tube; vm, vertebral muscles. In (A), (C-E) and (G) the bar=100 $\mu \mathrm{m}$, and in $(B)$ and $(F)$ the bar $=50 \mu \mathrm{m}$. 

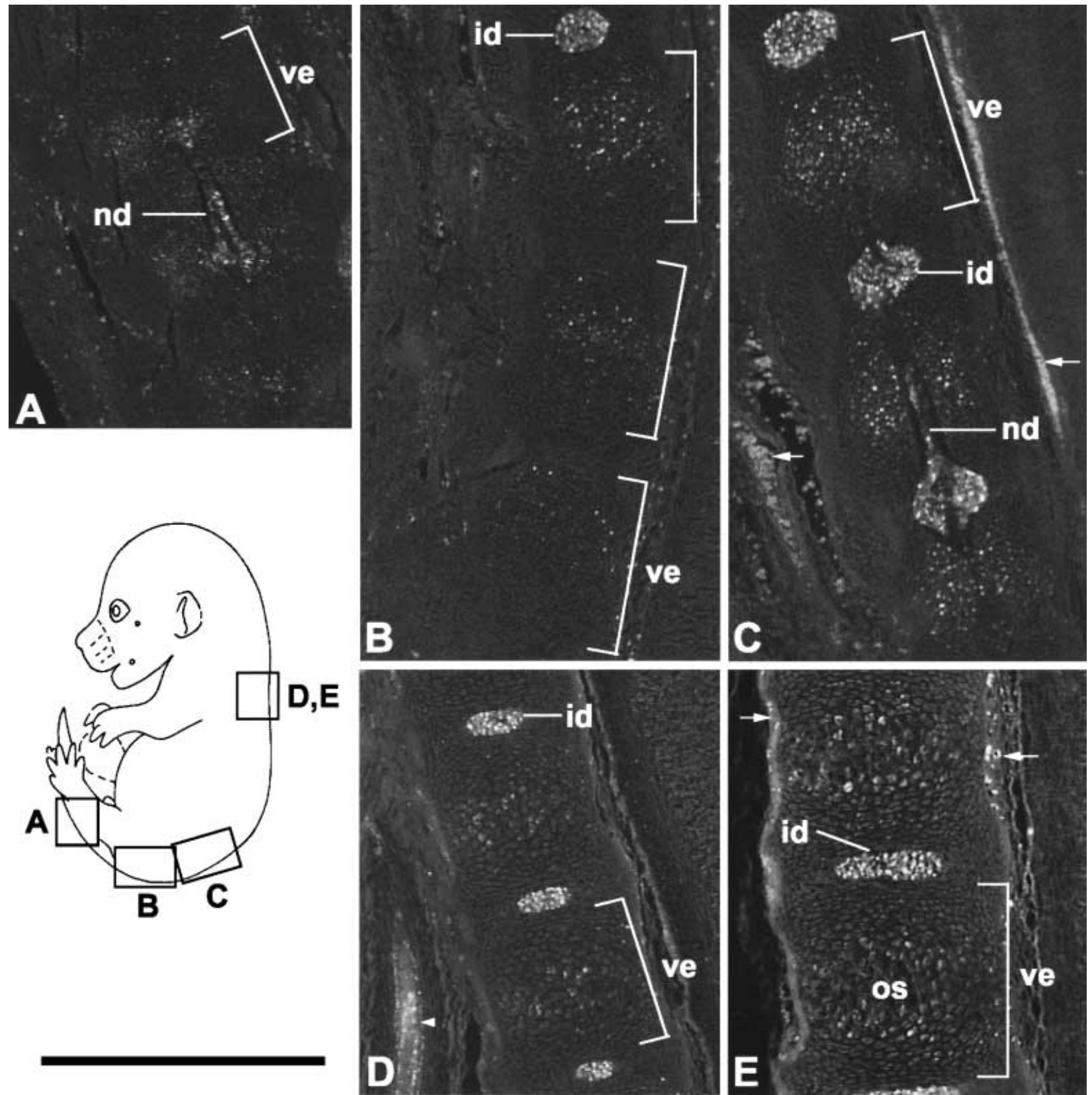

Figure 2 Localization of STC1 in the vertebrae along the rostro-caudal body axis. The positions of panels (A-E) are indicated in the diagram (adapted from Kaufman 1992). (A-D) are at E14.5 and (E) is at E15.5; (D) and (E) both show high thoracic vertebrae. (A) STC1 first appears in the condensing sclerotome, and (B) then disappears in the young chondrocytes (see the most caudal vertebra), but reappears as chondrocytes enter the prehypertrophic phase (see the most rostral vertebra). (C) STC1 staining is seen in the prehypertrophic chondrocytes of the vertebrae, but (D) decreases as the chondrocytes undergo hypertrophic changes. (E) One day later, STC1 staining remains in the layer of chondrocytes surrounding the ossifying core (os) of the vertebral body. The arrowhead in (D) indicates STC1 staining in esophageal epithelium. The arrows in (C) and (E) indicate false signals due to autofluorescence of blood cells. Each bracket indicates the domain of a vertebra. Other abbreviations: id, intervertebral disk; nd, notochord; ve, vertebra. Bar $=500 \mu \mathrm{m}$.

metabolism (Yoshiko et al. 1999). Our detailed analysis on mouse embryos revealed that the distribution of STC1 in endochondral bones was mainly restricted to the zone where chondrocytes undergo transition from a proliferating to a hypertrophic phenotype. The cells in this zone are considered to coordinate the rate of chondrocyte 

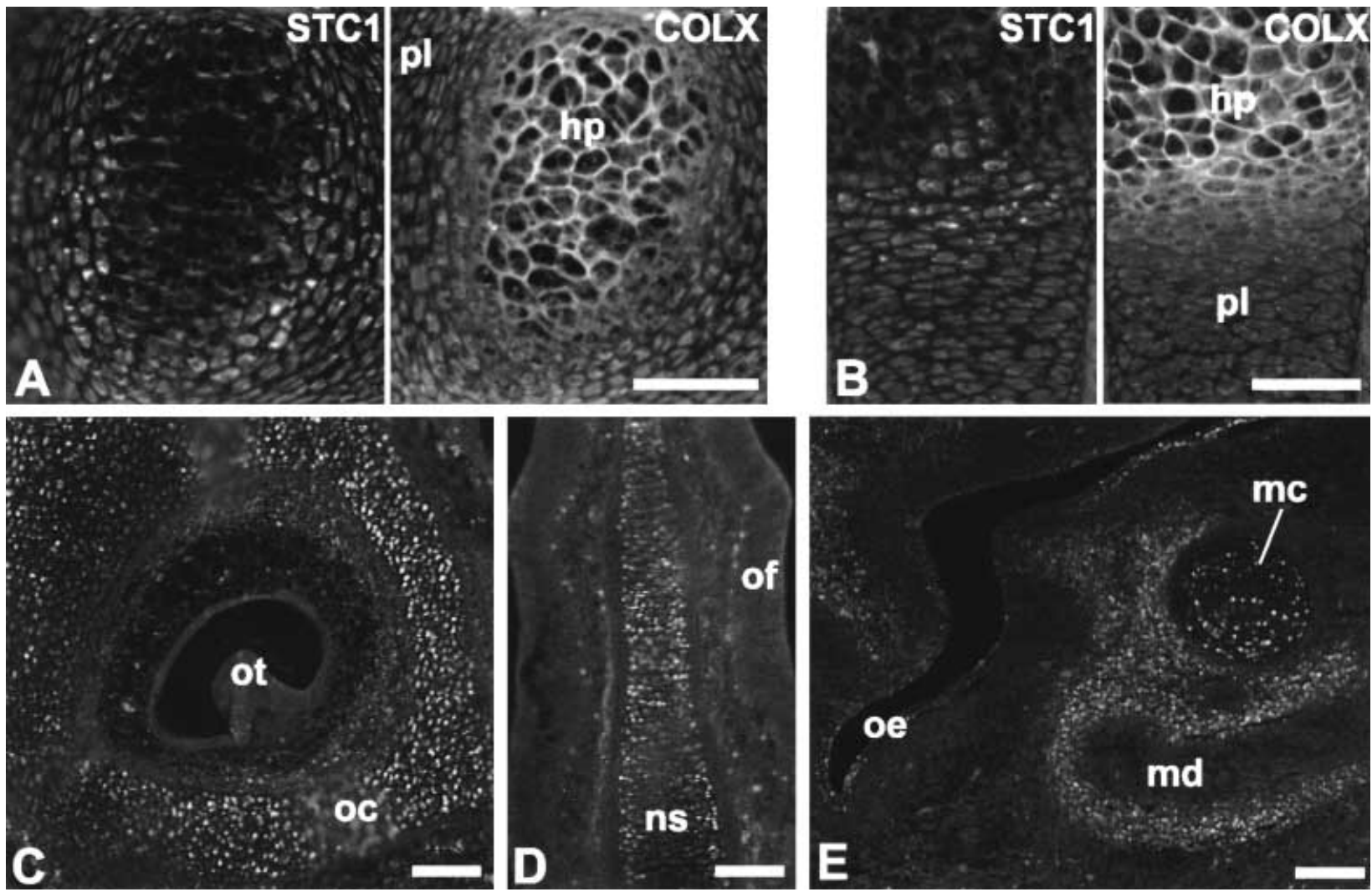

Figure 3 Distribution of STC1 in chondrogenic and osteogenic tissues. (A) In the vertebral body at E15.5, STC1 is localized in a circular layer of chondrocytes between the proliferative ( $\mathrm{pl}$ ) and hypertrophic (hp) zones outside the central core of hypertrophic cartilage marked by collagen X (COLX) staining (in the neighboring section). (B) At E15.5, STC1 is present in the transitional layer in the ulna of the forelimb (left panel), adjacent to the COLX-positive hypertrophic chondrocytes (right panel). STC1 is also found in (C) the chondrocytes of the otic capsule (oc) at E15·5, and in (D) the nasal septum (ns) at E15·5. (E) At E13.5, STC1 is seen in the Meckel's cartilage $(\mathrm{mc})$ and in the mesenchymal condensation of the mandible (md). Additional abbreviations: oe, oral epithelium; of, olfactory epithelium; ot, otic sensory epithelium. Bar $=100 \mu \mathrm{m}$.

maturation (Erlebacher et al. 1995). Parathyroid hormonerelated peptide $(\mathrm{PTHrP})$ receptor has also been reported to be localized to the same transitional zone (Lee et al. 1996). Activation of the PTHrP receptor by PTHrP delays chondrocytic maturation in this transitional layer to promote elongation of endochondral bone (Amizuka et al. 1994, Lee et al. 1996). In fish, STC has an anti-hypercalcemic action (Fontaine 1964, So \& Fenwick 1979, Lafeber \& Perry 1988), whereas human PTHrP was identified as a causative agent for malignancy-associated hypercalcemia (Suva et al. 1987). It would be interesting to investigate whether these contrasting physiological actions will be reflected at the local tissue level; that is, whether STC1 and PTHrP have opposing effects on chondrocytic maturation during endochondral bone formation.

Our data also show that STC1 is present in developing skeletal and cardiac muscles, implying possible involvement of STC1 in myogenic differentiation. In skeletal muscles, terminal myogenic differentiation involves fusion of myoblasts into multi-nucleated myotubes, which is regulated by calcium-dependent processes such as cell adhesion (Przybylski et al. 1994, Eng et al. 1997). Based on the known role of fish STC in calcium homeostasis, it is tempting to speculate that STC1 may modulate myocyte differentiation by regulating calcium-dependent myoblast fusion.

Although high levels of STC1 mRNA have been detected in whole mouse embryos using Northern blot analysis (Varghese et al. 1998), the distribution of the protein in the tissues remained unknown. The results of our study have shown that STC1 is distributed in different embryonic tissues in a stage- and cell type-specific pattern. The pattern of STC1 localization is most likely reflecting the site of action of STC1 rather than the site of its synthesis. A recent report shows that in the kidney, STC1 is found exclusively in the segments that do not express the gene (Wong et al. 1998). This is also in agreement with previous reports that secreted hormones and growth factors, for example PTHrP (Lee et al. 1996), are often 

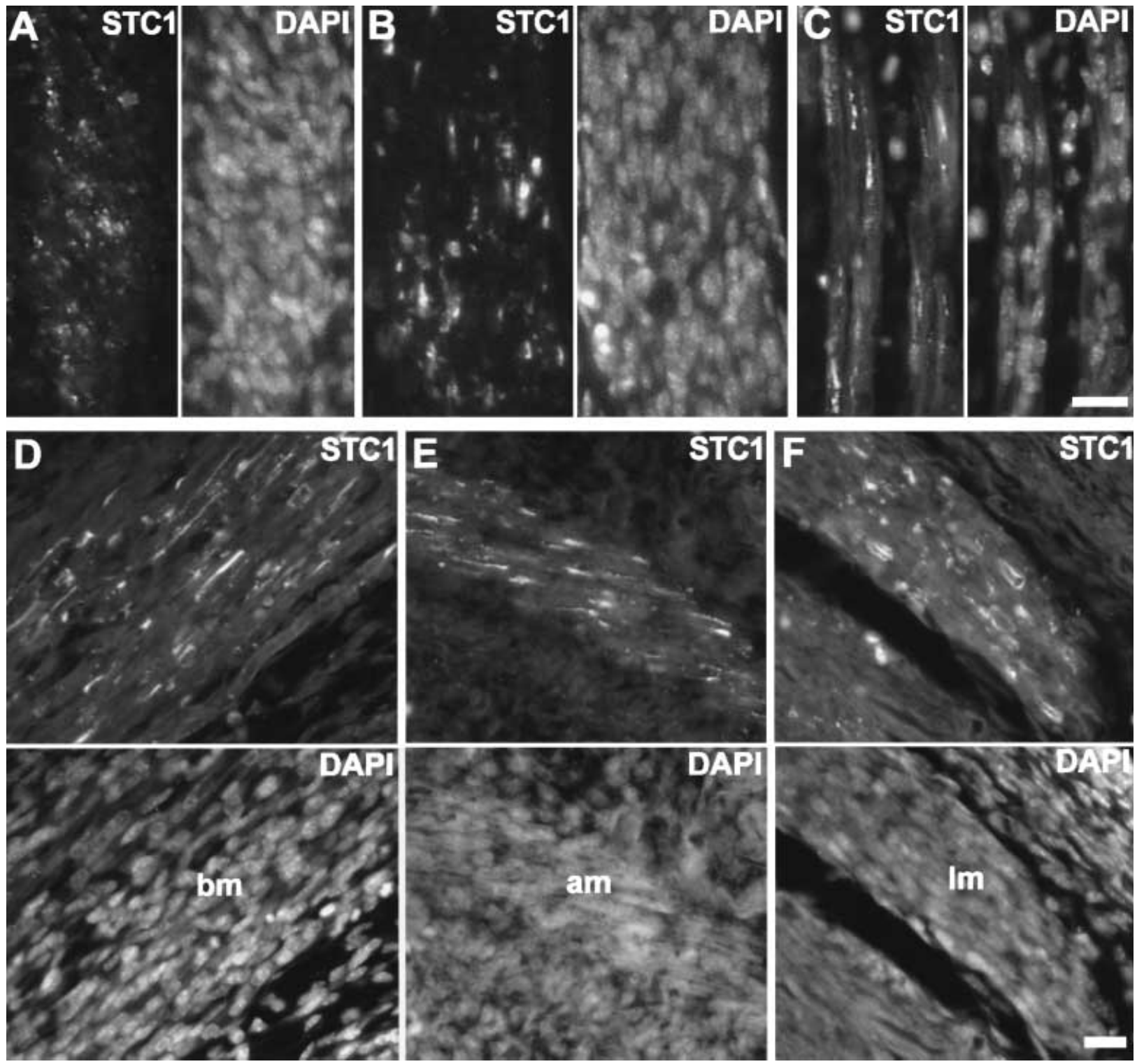

Figure 4 Distribution of STC1 in skeletal muscles. STC1 and DAPI staining is shown for each section. (A) At E12.5, STC1 is present in the myoblasts of the condensed myotome. (B) At E13.5, STC1 becomes more prominent as the myoblasts align in preparation for fusion. (C) At E15.5, STC1 staining in myotubes is patchy. Similar STC1 staining is found in three skeletal muscle groups: (D) the back, (E) the abdominal wall and (F) the limb at E13.5. Abbreviations: am, abdominal wall muscles; bm, back muscles; Im, limb muscles. Bar $=20 \mu \mathrm{m}$.

detected in the target cells rather than at the sites of transcription.

In summary, our data show that STC1 staining is localized predominantly to the myogenic and chondrogenic tissues, suggesting a role for STC1 in musculoskeletal development. As calcium is known to play an important role in the development of these tissues it is perhaps not surprising to find an involvement of STC1, because the homologous protein in the fish regu- lates calcium homeostasis. The detailed molecular mechanisms of the actions of STC1 are unknown. However, an obvious starting point would be to examine the possible interactions of STC1 with other relevant factors, including bcl2 (Amling et al. 1997), PTHrP (Lee et al. 1996) and cGMP-dependent protein kinase II (Pfeifer et al. 1996), that are primarily localized in the transitional layer between proliferating and hypertrophic chondrocytes. 

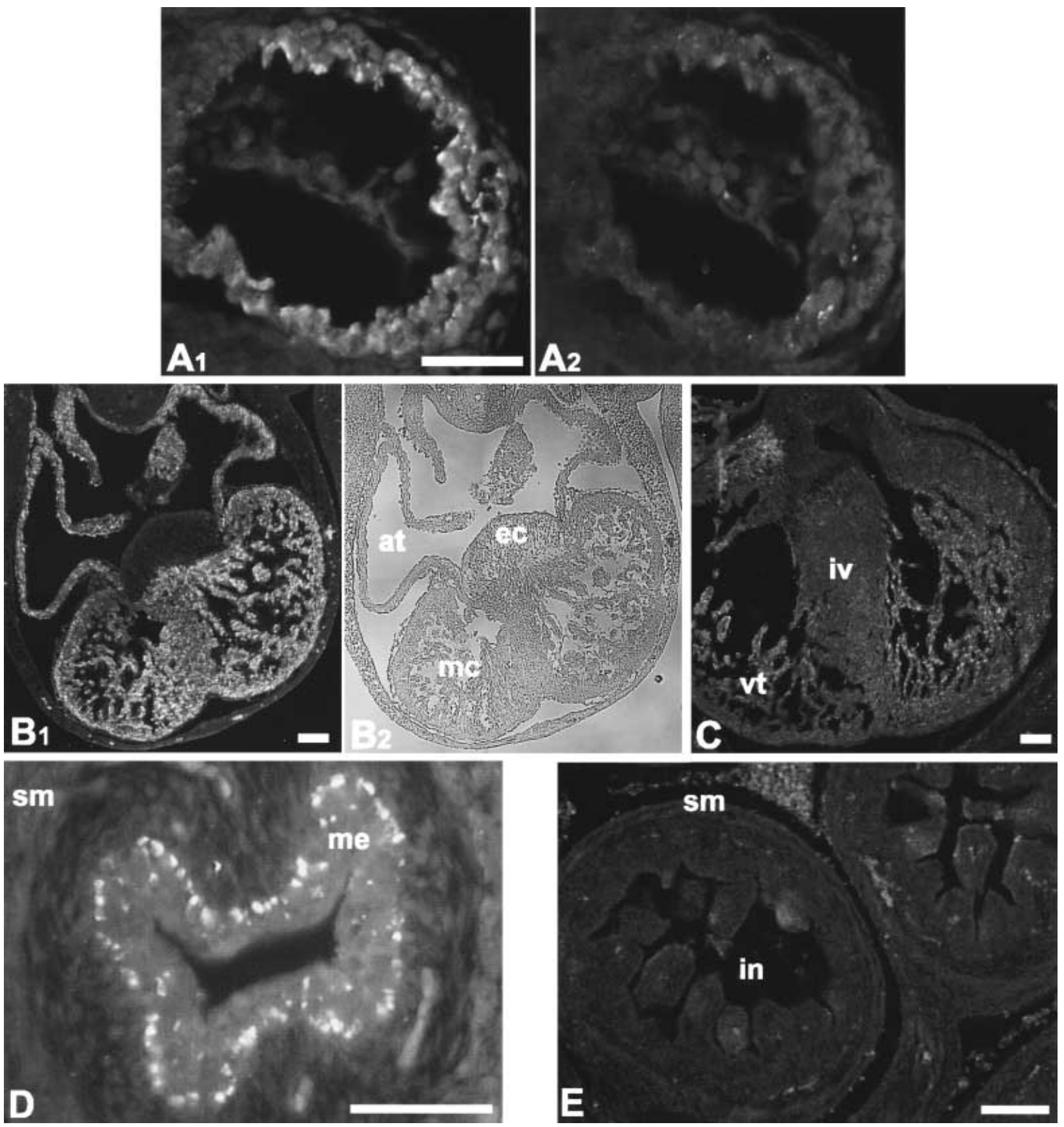

Figure 5 Distribution of STC1 in cardiac and smooth muscles, and epithelium. (A) Two consecutive sections of an E8.5 embryo were immunostained with the anti-STC1 antibody preabsorbed with BSA $\left(\mathrm{A}_{1}\right)$ or baculoviral rhSTC1 $\left(\mathrm{A}_{2}\right)$. The positive heart staining in $\left(\mathrm{A}_{1}\right)$ and its absence in $\left(A_{2}\right)$ demonstrates the specificity of the STC1 antibody. (B) In the heart of an E11.5 embryo, STC1 is present in the ventricular and atrial (at) myocardium (mc), but absent from the endocardial cushion $(\mathrm{ec})\left(\mathrm{B}_{1}\right)$; $\left(\mathrm{B}_{2}\right)$ is the bright field image. (C) Less STC1 is found in the ventricular trabeculae (vt) at E13.5. STC1 is absent from the smooth muscles of (D) the esophagus and (E) the intestine, both shown at E15.5. STC1 is present in the basal layer of the stratified mucous epithelium (me) of the esophagus (D) but absent from the mucous epithelium of intestine (in) (E). Additional abbreviations: iv, interventricular septum; sm, smooth muscles. In (A) and (D) the bar $=50 \mu \mathrm{m}$, and in (B), (C) and (E) the bar $=100 \mu \mathrm{m}$. 


\section{Acknowledgements}

This work was supported by a project grant from the National Health and Medical Research Council of Australia, and the Carcinogenesis Fellowship of the New South Wales Cancer Council. The authors thank Derek Jellinek for baculoviral rhSTC1, Dr Olena Jacenko for the anti-COLX antibody, Drs Peter Rowe, Phil Robinson and Edna Hardeman for comments on the manuscript and Lindy Hodgkin for assistance with the manuscript.

\section{References}

Amizuka N, Warshawsky H, Henderson JE, Goltzman D \& Karaplis AC 1994 Parathyroid hormone-related peptide-depleted mice show abnormal epiphyseal cartilage development and altered endochondral bone formation. Journal of Cell Biology 126 1611-1623.

Amling M, Neff L, Tanaka S, Inoue D, Kuida K, Weir E, Philbrick WM, Broadus AE \& Baron R 1997 Bcl-2 lies downstream of parathyroid hormone-related peptide in a signaling pathway that regulates chondrocyte maturation during skeletal development. Journal of Cell Biology 136 205-213.

Butkus A, Roche PJ, Fernley RT, Haralambidis J, Penschow JD, Rya GB, Trahair JF, Tregear GW \& Coghlan JP 1987 Purification and cloning of a corpuscles of Stannius protein from Anguilla australis. Molecular and Cellular Endocrinology 54 123-133.

Butkus A, Yates NA, Copp DH, Milliken C, McDougall JH, Roche PJ, Tregear GW \& Coghlan JP 1989 Processing and bioactivity of the corpuscles of Stannius protein of the Australian eel. Fish Physiology and Biochemistry 7 359-365.

Chang ACM \& Reddel RR 1998 Identification of a second stanniocalcin cDNA in mouse and human: stanniocalcin 2. Molecular and Cellular Endocrinology 141 95-99.

Chang AC-M, Janosi J, Hulsbeek M, De Jong D, Jeffrey KJ, Noble JR \& Reddel RR 1995 A novel human cDNA highly homologous to the fish hormone stanniocalcin. Molecular and Cellular Endocrinology 112 241-247.

Chang AC-M, Dunham MA, Jeffrey KJ \& Reddel RR 1996 Molecular cloning and characterization of mouse stanniocalcin cDNA. Molecular and Cellular Endocrinology 124 185-187.

De Niu P, Olsen HS, Gentz R \& Wagner GF 1998 Immunolocalization of stanniocalcin in human kidney. Molecular and Cellular Endocrinology 137 155-159.

DiMattia GE, Varghese R \& Wagner GF 1998 Molecular cloning and characterization of stanniocalcin-related protein. Molecular and Cellular Endocrinology 146 137-140.

Eng H, Herrenknecht K, Semb H, Starzinski-Powitz A, Ringertz N \& Gullberg D 1997 Effects of divalent cations on M-cadherin expression and distribution during primary rat myogenesis in vitro. Differentiation 61 169-176.

Erlebacher A, Filvaroff EH, Gitelman SE \& Derynck R 1995 Toward a molecular understanding of skeletal development. Cell $\mathbf{8 0}$ 371-378.

Fontaine M 1964 Corpuscles de Stannius et régulation ionique (Ca, K, $\mathrm{Na}$ ) du milieu intérieur de l'anguille (Anguilla anguilla L.). Comdtes Rendus de L'Academie des Sciences 259 875-878.

Ishibashi K, Miyamoto K, Taketani Y, Morita K, Takeda E, Sasaki S \& Imai I 1998 Molecular cloning of a second human stanniocalcin homologue (STC2). Biochemical and Biophysical Research Communications 250 252-258.

Iyer VR, Eisen MB, Ross DT, Schuler G, Moore T, Lee JCF, Trent JM, Staudt LM, Hudson J Jr, Boguski MS, Lashkari D, Shalon D, Botstein D \& Brown PO 1999 The transcriptional program in the response of human fibroblasts to serum. Science 283 83-87.
Kaufman MH 1992 The Atlas of Mouse Development. London: Academic Press.

Kwan KM, Pang MKM, Zhou S, Cowan SK, Kong RYC, Pfordte T, Olsen BR, Sillence DO, Tam PPL \& Cheah KSE 1997 Abnormal compartmentalization of cartilage matrix components in mice lacking collagen X: implications for function. Journal of Cell Biology 136 459-471.

Lafeber FPJG \& Perry SF 1988 Experimental hypercalcemia induces hypocalcin release and inhibits branchial $\mathrm{Ca}^{2+}$ influx in freshwater trout. General and Comparative Endocrinology 72 136-143.

Lee K, Lanske B, Karaplis AC, Deeds JD, Kohno H, Nissenson RA, Kronenberg HM \& Segre GV 1996 Parathyroid hormone-related peptide delays terminal differentiation of chondrocytes during endochondral bone development. Endocrinology 137 5109-5118.

Lu M, Wagner GF \& Renfro JL 1994 Stanniocalcin stimulates phosphate reabsorption by flounder renal proximal tubule in primary culture. American Journal of Physiology 267 R1356-R1362.

Olsen HS, Cepeda MA, Zhang QQ, Rosen CA, Vozzolo BL \& Wagner GF 1996 Human stanniocalcin: a possible hormonal regulator of mineral metabolism. Proceedings of the National Academy of Sciences of the USA 93 1792-1796.

Pfeifer A, Aszodi A, Seidler U, Ruth P, Hofmann F \& Fässler R 1996 Intestinal secretory defects and dwarfism in mice lacking cGMP-dependent protein kinase II. Science 274 2082-2086.

Przybylski RJ, Szigeti V, Davidheiser S \& Kirby AC 1994 Calcium regulation of skeletal myogenesis. II. Extracellular and cell surface effects. Cell Calcium 15 132-142.

So YP \& Fenwick JC 1979 in vivo and in vitro effects of Stannius corpuscle extract on the branchial uptake of ${ }^{45} \mathrm{Ca}$ in stanniectomized North American eels (Anguilla rostrata). General and Comparative Endocrinology 37 143-149.

Stannius H 1839 Nebennieren bei knochenfischen. Archives of Anatomical Physiology 6 97-101.

Sterba T, Wagner GF, Schroedter IC \& Friesen HG 1993 in situ detection and distribution of stanniocalcin mRNA in the corpuscles of Stannius of sockeye salmon, Oncorhynchus nerka. Molecular and Cellular Endocrinology 90 179-185.

Suva LJ, Winslow GA, Wettenhall REH, Hammonds RG, Moseley JM, Diefenbach-Jagger H, Rodda CP, Kemp BE, Rodriguez H, Chen EY, Hudson PJ, Martin TJ \& Wood WI 1987 A parathyroid hormone-related protein implicated in malignant hypercalcemia: cloning and expression. Science 237 893-896.

Varghese R, Wong CKC, Deol H, Wagner GF \& DiMattia GE 1998 Comparative analysis of mammalian stanniocalcin genes. Endocrinology 139 4714-4725.

Wagner GF, Hampong M, Park CM \& Copp DH 1986 Purification, characterization, and bioassay of teleocalcin, a glycoprotein from salmon corpuscles of Stannius. General and Comparative Endocrinology 63 481-491.

Wagner GF, Gellersen B \& Friesen HG 1989 Primary culture of teleocalcin cells from rainbow trout corpuscles of Stannius: regulation of teleocalcin secretion by calcium. Molecular and Cellular Endocrinology 62 31-39.

Wagner GF, Milliken C, Friesen HG \& Copp DH 1991 Studies on the regulation and characterization of plasma stanniocalcin in rainbow trout. Molecular and Cellular Endocrinology 79 129-138.

Wagner GF, DiMattia GE, Davie JR, Copp DH \& Friesen HG 1992 Molecular cloning and cDNA sequence analysis of coho salmon stanniocalcin. Molecular and Cellular Endocrinology 90 7-15.

Wagner GF, Vozzolo BL, Jaworski E, Haddad M, Kline RL, Olsen HS, Rosen CA, Davidson MB \& Renfro JL 1997 Human stanniocalcin inhibits renal phosphate excretion in the rat. Journal of Bone and Mineral Research 12 165-171.

Wong CKC, Ho MA \& Wagner GF 1998 The co-localization of stanniocalcin protein, mRNA and kidney cell markers in the rat kidney. Journal of Endocrinology 158 183-189. 
Yoshiko Y, Son A, Maeda S, Igarashi A, Takano S, Hu J \& Maeda N 1999 Evidence for stanniocalcin gene expression in mammalian bone. Endocrinology 140 1869-1874.

Zhang K, Westberg JA, Paetau A, Von Boguslawsky K, Lindsberg P, Erlander M, Guo H, Su J, Olsen HS \& Andersson LC 1998 High expression of stanniocalcin in differentiated brain neurons. American Journal of Pathology 153 439-445.
Received 26 July 1999

Revised manuscript received 30 November 1999

Accepted 22 December 1999 